\title{
Discordance between clinical and pathological TNM classification: influence on results of treatment and prognosis in patients with laryngeal cancer
}

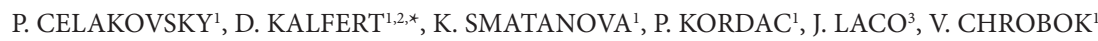 \\ ${ }^{1}$ Department of Otorhinolaryngology and Head and Neck Surgery, University Hospital Hradec Kralove, Charles University, Faculty of Medicine \\ in Hradec Kralove, Czech Republic; 2Department of Otorhinolaryngology and Head and Neck Surgery, University Hospital Motol, Charles \\ University, First Faculty of Medicine, Czech Republic; 3The Fingerland Department of Pathology, University Hospital Hradec Kralove, Charles \\ University, Faculty of Medicine in Hradec Kralove, Czech Republic
}

${ }^{*}$ Correspondence: david.kalfert@email.cz

Received May 16, 2016/ Accepted October 28, 2016

\begin{abstract}
The goals of this retrospective cohort study were to compare the results of clinical and pathological TNM staging in patients with laryngeal squamous cell carcinoma and to determine the impact of the discordance on prognosis and treatment results. A total of 124 patients with laryngeal cancer, primarily indicated for surgical treatment, were enrolled. The concordance or discordance between the clinical and pathological staging was compared with the frequency of cancer relapse and diseasespecific survival. Other potential prognostic factors, like age, the stage and location of the primary tumor, the status of neck lymph nodes, histological margins, and an indication for postoperative radiotherapy, were also evaluated. A disparity in at least one component of TNM staging was found in 40 patients (32\%). The discordance had significant negative influence on both disease-free survival (DSF) and disease-specific survival (DSS). Other significant negative prognostic factors were the stage of the primary tumor, nodal status and postoperative radiotherapy. Our results indicate that the discordance between clinical and pathological staging affects the results of cancer treatment significantly. Some improvement can be probably achieved with higher preoperative diagnostic method accuracy.
\end{abstract}

Key words: TNM staging, clinical TNM classification, pathological TNM classification, laryngeal cancer, prognosis

The TNM classification is considered to be the most reliable system defining the extent of the primary tumor and its regional and distant metastases. Correct TNM staging is fundamental for therapeutic decisions and also plays an important role as a prognostic factor.

Clinical TNM (cTNM) classification is based on the findings of physical examination, endoscopy and imaging. To determine pathological TNM (pTNM) classification, a detailed histopathological analysis of surgically removed tissue is necessary [1]. Recent studies show that none of the modern imaging modalities are able to verify the extent of the primary tumor accurately or to prove the presence of metastases in regional lymph nodes [2]. This is the main reason why in some patients, a discordance between cTNM and pTNM classification can be demonstrated. The aim of our study was to assess the percentage of the discordance between cTNM and pTNM staging in patients with laryngeal cancer and to determine the impact of the discordance on recurrence rate and disease prognosis.

\section{Patients and methods}

Patients. All patients after the primary surgical treatment of laryngeal cancer were included in the study. The time period 2001-2011 was considered and clinical records were evaluated retrospectively. An ethical approval was not considered necessary as the patients' data data were collected retrospectively. In total, 124 patients (111 men and 13 women) were analyzed; their ages ranged from 28 to 85 years (median 61 years, average 61 years). Glottic cancers $(77.4 \%)$ were more frequent than supraglottic cancers $(21.8 \%)$ and only one case of primary subglottic cancer was recorded $(0.8 \%)$. The pathological TNM staging of our patients was: Stage I in 59 patients (47.6\%), Stage II in 17 patients (13.7\%), Stage III in 25 patients $(20.2 \%)$ and Stage IV in 23 patients (18.5\%).

Treatment. As to the primary surgical treatment, a partial vertical laryngectomy (LE) using an external approach was performed in 68 patients (55\%), a total LE was carried out in 


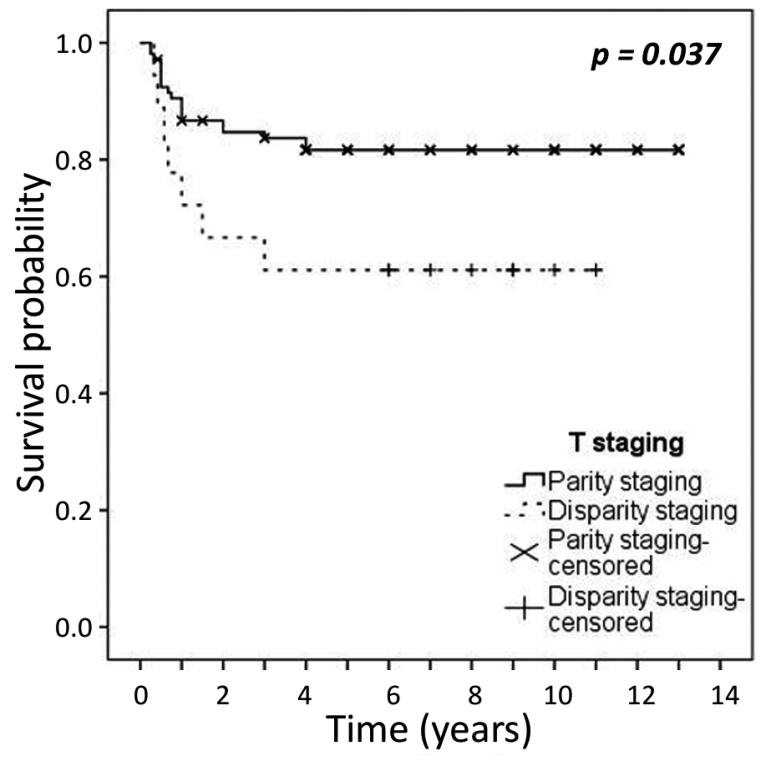

Figure 1. Disease-free survival (DFS) related to parity and disparity of T staging

41 patients (33\%) and a neck dissection was indicated in 53 patients (43\%). Seventy-four patients (60\%) also had adjuvant postoperative radiotherapy (radiochemotherapy).

Clinical TNM classification. The clinical TNM classification was assessed on the basis of the clinical examination and imaging (sonography and CT or MRI), the pathological TNM classification was determined by a histopathological analysis of surgical specimens (the primary tumor and neck lymph nodes).

Evaluation of concordance or discordance between cTNM and PTNM staging. The concordance or discordance between the clinical and pathological staging was compared with the frequency of cancer relapse and the disease-specific survival rate. Other potential prognostic factors like age, the stage and location of the primary tumor, the status of neck lymph nodes, histological margins and an indication for postoperative radiotherapy, were also evaluated.

Statistical analysis. All statistical analyses were performed using IBM SPSS Statistics (version 22.0; SPSS, IBM, Armonk,

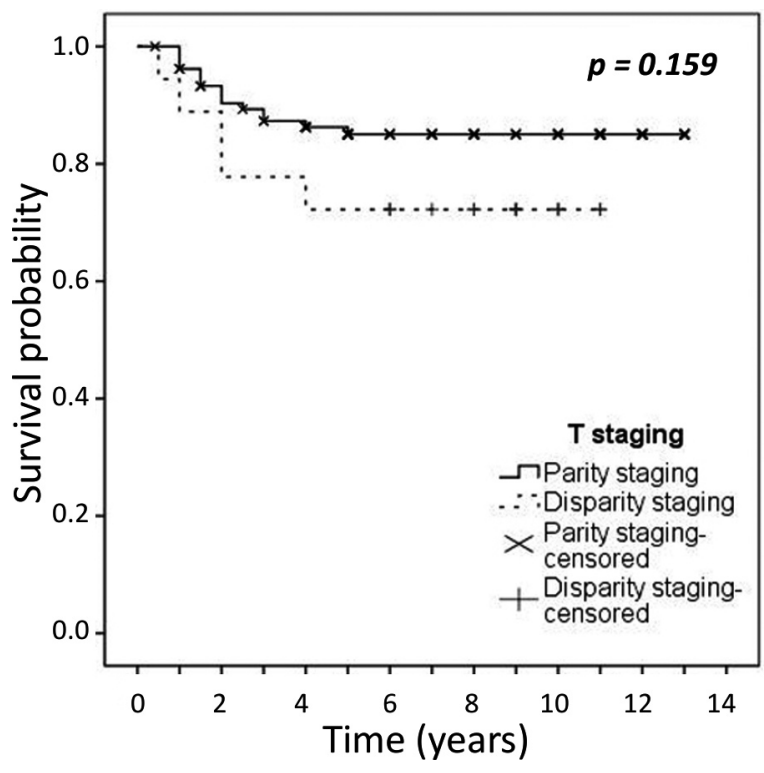

Figure 2. Disease-specific survival (DSS) related to parity and disparity of T staging

NY, USA). The statistical results were calculated using the Fisher exact test (two-tailed). The Kaplan-Meier's method was used to evaluate disease-free survival (DFS), overall survival (OS) and disease-specific survival (DSS). The log-rank test was used for the evaluation of other variables related to DFS and DSS. $P$-values lower than 0.05 were considered to be statistically significant in all statistical analyses.

\section{Results}

Discordance of clinical and pathological TNM staging. A disparity in at least one component of TNM staging was found in 40 patients (32\%). Fifteen patients showed a discordance in the primary tumor size $(\mathrm{T})$ and 22 patients in the classification of neck metastases $(\mathrm{N})$. Some disparity in both $\mathrm{T}$ and $\mathrm{N}$ staging was found in 3 cases. A disparity in $\mathrm{T}$ staging was more typical for glottic cancer compared to supraglottic cancer $(13.5 \%$ and $7.4 \%$ respectively, $p=0.519)$ and a disparity in $\mathrm{N}$ staging was significantly more frequently seen in the

Table 1. Discordance of TNM staging and cancer site

\begin{tabular}{|c|c|c|c|c|c|c|}
\hline \multirow{3}{*}{ Staging } & \multirow{3}{*}{ Variable } & \multicolumn{4}{|c|}{ Site of cancer } & \multirow{3}{*}{$P$-value ${ }^{\star}$} \\
\hline & & \multicolumn{2}{|c|}{ Glottic } & \multicolumn{2}{|c|}{ Supraglottic } & \\
\hline & & $\mathbf{n}$ & $\%$ & $\mathbf{n}$ & $\%$ & \\
\hline \multirow{2}{*}{$\mathrm{T}$} & Parity & 83 & 86.5 & 25 & 92.6 & \multirow{2}{*}{$0.518^{\mathrm{a}}$} \\
\hline & Disparity & 13 & 13.5 & 2 & 7.4 & \\
\hline \multirow{2}{*}{$\mathrm{N}$} & Parity & 85 & 88.6 & 16 & 59.3 & \multirow{2}{*}{$0.001^{\mathrm{a}}$} \\
\hline & Disparity & 11 & 11.4 & 11 & 40.7 & \\
\hline
\end{tabular}

${ }^{a}$ Fisher exact test, ${ }^{*}$ Difference is significant at the significance level $p<0.05$ 
cases of supraglottic cancer compared to glottic cancer $(11.4 \%$ and $40.7 \%$ respectively, $p=0.001$ ) (Table 1 ).

Recurrence of laryngeal cancer. A recurrence or persistence of laryngeal cancer was confirmed during the follow-up in 26 cases $(21 \%)$. While a disparity in $\mathrm{N}$ stage did not influence the frequency of cancer recurrence $(p=1.000)$, a disparity in $\mathrm{T}$ stage was non-significantly more often associated with a recurrent tumor $(p=0.059)$. The recurrence rate was significantly higher where pT was higher than cT $(p=0.008)$ (Table 2). Disease-free survival (DFS) was significantly shorter in the patients with a discordance in $\mathrm{T}$ stage than in the patients with a concordance in T stage $(p=0.037)$ (Figure 1). Considering other variables, only the size of the primary tumor had a sta- tistically significant influence on the cancer recurrence rate. The higher frequency of cancer recurrence was also associated with the positivity of cervical lymph nodes, the positivity of histological margins and an indication for postoperative radiotherapy. However, these results were not statistically significant. The recurrence rate was influenced neither by the primary tumor site (supraglottic, glottic), nor by the number of removed lymph nodes (Table 3).

Specific mortality. During the follow-up, 20 patients $(16.3 \%)$ died related to laryngeal cancer. Specific mortality was significantly higher in the cases with a disparity in $\mathrm{T}$ stage, especially when $\mathrm{pT}$ stage was higher than cT stage $(p=0.043)$ (Table 4). Simultaneously, disease-specific survival was non-

Table 2. Discordance of TNM staging and cancer recurrence

\begin{tabular}{|c|c|c|c|c|c|c|}
\hline \multirow{3}{*}{\multicolumn{2}{|c|}{ Comparison of $\mathrm{cT}$ and $\mathrm{pT}$}} & \multicolumn{4}{|c|}{ Recurrence } & \multirow{4}{*}{$P$-value } \\
\hline & & \multicolumn{2}{|c|}{ No } & \multicolumn{2}{|c|}{ Yes } & \\
\hline & & $\mathbf{n}$ & $\%$ & $\mathbf{n}$ & $\%$ & \\
\hline Parity & & 87 & 82.1 & 19 & 17.9 & \\
\hline \multirow{3}{*}{ Disparity } & Total & 11 & 61.1 & 7 & 38.9 & $0.059^{\mathrm{a}}$ \\
\hline & $\mathrm{cT}>\mathrm{pT}$ & 5 & 100.0 & 0 & 0 & $0.586^{\mathrm{a}}$ \\
\hline & $\mathrm{cT}<\mathrm{pT}$ & 6 & 46.2 & 7 & 53.8 & $0.008^{\mathrm{a}}$ \\
\hline
\end{tabular}

${ }^{a}$ Fisher exact test, ${ }^{*}$ Difference is significant at the significance level $p<0.05$

Table 3. Other variables and cancer recurrence

\begin{tabular}{|c|c|c|c|c|c|c|}
\hline \multirow{3}{*}{ Variable } & & \multicolumn{4}{|c|}{ Recurrence } & \multirow{3}{*}{$P$-value ${ }^{\star}$} \\
\hline & & \multicolumn{2}{|c|}{ No } & \multicolumn{2}{|c|}{ Yes } & \\
\hline & & $\mathbf{n}$ & $\%$ & $\mathbf{n}$ & $\%$ & \\
\hline \multirow{2}{*}{$\mathrm{pT}$} & $\mathrm{T} 1-\mathrm{T} 2$ & 72 & 87.8 & 10 & 12.2 & \multirow{2}{*}{$0.001^{\mathrm{a}}$} \\
\hline & $\mathrm{T} 3-\mathrm{T} 4$ & 26 & 61.9 & 16 & 38.1 & \\
\hline \multirow{2}{*}{$\mathrm{pN}$} & No & 87 & 81.3 & 20 & 18.7 & \multirow{2}{*}{$0.195^{\mathrm{a}}$} \\
\hline & $\mathrm{N}+$ & 11 & 64.7 & 6 & 35.3 & \\
\hline \multirow{2}{*}{ Histological margins } & Negative & 87 & 81.3 & 20 & 18.7 & \multirow{2}{*}{$0.195^{\mathrm{a}}$} \\
\hline & Positive & 11 & 64.7 & 6 & 35.3 & \\
\hline \multirow{2}{*}{ Postoperative radiotherapy } & No & 63 & 85.1 & 11 & 14.9 & \multirow{2}{*}{$0.071^{\mathrm{a}}$} \\
\hline & Yes & 35 & 70.0 & 15 & 30.0 & \\
\hline
\end{tabular}

${ }^{a}$ Fisher exact test, ${ }^{*}$ Difference is significant at the significance level $p<0.05$

Table 4. Discordance of TNM staging and specific mortality

\begin{tabular}{|c|c|c|c|c|c|c|}
\hline \multirow{3}{*}{\multicolumn{2}{|c|}{ Comparison of $\mathrm{cT}$ and $\mathrm{pT}$}} & \multicolumn{4}{|c|}{ Mortality } & \multirow{4}{*}{$P$-value } \\
\hline & & \multicolumn{2}{|c|}{ No } & \multicolumn{2}{|c|}{ Yes } & \\
\hline & & $\mathbf{n}$ & $\%$ & $\mathbf{n}$ & $\%$ & \\
\hline Parity & & 91 & 85.8 & 15 & 14.2 & \\
\hline \multirow{3}{*}{ Disparity } & Total & 13 & 72.2 & 5 & 27.8 & $0.168^{\mathrm{a}}$ \\
\hline & $\mathrm{cT}>\mathrm{pT}$ & 5 & 100.0 & 0 & 0.0 & $0.611^{\mathrm{a}}$ \\
\hline & $\mathrm{cT}<\mathrm{pT}$ & 8 & 61.5 & 5 & 38.5 & $0.043^{\mathrm{a}}$ \\
\hline
\end{tabular}

${ }^{a}$ Fisher exact test, ${ }^{\star}$ Difference is significant at the significance level $p<0.05$ 
significantly shorter in the cases with a discordance in T stage than in the patients with a concordance in T stage $(p=0.159$, Figure 2). On the other hand, a disparity in $\mathrm{N}$ stage did not influence specific mortality significantly.

Other significant negative prognostic factors (associated with higher specific mortality) were the size of the primary tumor, a positive nodal status and postoperative radiotherapy. Specific mortality was not influenced by the tumor site (supraglottic, glottic), by the positivity of histological margins or by the number of removed neck lymph nodes (Table 5).

\section{Discussion}

Currently, malignant tumors are classified according to the $7^{\text {th }}$ edition of TNM classification [1]. Determination of tumor stage is fundamental to the planning of an appropriate oncologic treatment, and also plays an important role as a prognostic factor. However, an exact determination of clinical staging depends on the accuracy of diagnostic methods, used for preoperative staging of cancer.

The accuracy of preoperative clinical examination, endoscopy and imaging in glottic cancer was studied by Zbären et al. $[3,4]$. His studies showed that clinical evaluation failed to identify the tumor invasion of the laryngeal cartilages and extralaryngeal soft tissues, resulting in a low staging accuracy (55\%). The combination of clinical evaluation and either computed tomography (CT) or magnetic resonance imaging (MRI) resulted in a significantly improved staging accuracy ( $80 \%$ vs $87 \%$, respectively). Similar results concerning the accuracy of both CT and MRI for the staging of laryngeal glottic cancer (sensitivity $88 \%$ and specificity $84 \%$ ) were also published by Kim et al. [5] and Kuno et al. [6]. A frequent failure of pre-therapeutic staging (combining endoscopy and $\mathrm{CT}$ ) of endolaryngeal cancer involving anterior commissure was confirmed by Foucher et al. [7]. In his results, $25 \%$ of cT2 and $33 \%$ of cT3 laryngeal tumors were reclassified to pT4 after the histopathological examination. Like anatomic imaging, functional imaging with fluorine-18 fluorodeoxyglucose (FDG) positron emission tomography (PET) has been incor- porated into the management of oncologic patients. In the management of head and neck tumors, however, the added value of FDG PET on top of CT or MRI appears limited and still deserves further clinical evaluation [8].

Precise detecting of neck lymph node metastases is also a big challenge. Nowadays, there is no imaging technique which would show $100 \%$ accuracy in detecting lymph node metastases. Clinical examination, including the newest imaging modalities, gives false negative results in about $20-30 \%$ cases $[9,10]$. Microscopic examination of dissected lymph nodes still remains the gold standard for the detection of lymph node metastases. However, if a lymph node is examined only by one central section, micrometastases, which are typically localized in the subcapsular sinuses of lymph nodes, are likely to be missed [11]. For this reason, it is very difficult to diagnose micrometastases using routine histopathological examinations $[10,12]$. Many authors state significantly increased detection rate of micrometastases by examining serial histological sections in combination with immunohistochemical or molecular procedures [13-15]. However, the fact that these methods are very time-consuming together with their higher cost hampers their wider use in clinical practice. Positive results in head and neck cancer patients with clinical N0 stage vary widely from 2 to $58 \%[13,16-19]$, which indicates that the detection methods are not united and the percentage of positive results depends on the experience of the histopathologist and also on the stage of the disease and the primary tumor site.

In current literature, only a limited number of studies focus on the accuracy of cTNM and pTNM staging in head and neck cancer patients. Koch et al. [20] compared cTNM and pTNM classification in a large group of 501 patients with head and neck cancer. A disparity between cTNM and pTNM staging was proven in almost $50 \%$ of cases. According to the author, both cTNM and pTNM classification showed a strong association between the stage and overall survival. However, the authors did not evaluate site-specific head and neck cancer individually and there is also no correlation of a disparity in $\mathrm{c}$ and $\mathrm{p}$ staging with the treatment results.

Table 5. Other variables and specific mortality

\begin{tabular}{|c|c|c|c|c|c|c|}
\hline \multirow{3}{*}{ Variable } & & \multicolumn{4}{|c|}{ Death related to laryngeal cancer } & \multirow{3}{*}{$P$-value ${ }^{*}$} \\
\hline & & \multicolumn{2}{|c|}{ No } & \multicolumn{2}{|c|}{ Yes } & \\
\hline & & $\mathbf{n}$ & $\%$ & $\mathbf{n}$ & $\%$ & \\
\hline \multirow{2}{*}{$\mathrm{pT}$} & $\mathrm{T} 1-\mathrm{T} 2$ & 78 & 95.1 & 4 & 4.9 & \multirow{2}{*}{$<0.001^{\mathrm{a}}$} \\
\hline & $\mathrm{T} 3-\mathrm{T} 4$ & 26 & 61.9 & 16 & 38.1 & \\
\hline \multirow{2}{*}{$\mathrm{pN}$} & No & 94 & 87.9 & 13 & 12.1 & \multirow{2}{*}{$0.007^{\mathrm{a}}$} \\
\hline & $\mathrm{N}+$ & 10 & 58.8 & 7 & 41.2 & \\
\hline \multirow{2}{*}{ Histological margins } & Negative & 90 & 84.1 & 17 & 15.9 & \multirow{2}{*}{$1.000^{\mathrm{a}}$} \\
\hline & Positive & 14 & 82.4 & 3 & 17.6 & \\
\hline \multirow{2}{*}{ Postoperative radiotherapy } & No & 68 & 91.9 & 6 & 8.1 & \multirow{2}{*}{$0.005^{\mathrm{a}}$} \\
\hline & Yes & 36 & 72.0 & 14 & 28.0 & \\
\hline
\end{tabular}

${ }^{a}$ Fisher exact test, $*$ Difference is significant at the significance level $p<0.05$ 
In our study, we found a disparity between cTNM and pTNM classification in 32\% of laryngeal cancer patients. A disparity in $\mathrm{T}$ stage was more typical for glottic cancer and a disparity in $\mathrm{N}$ stage was more frequent in supraglottic cancer patients. While a disparity in $\mathrm{N}$ stage did not influence the results of the treatment, a disparity in $\mathrm{T}$ stage was associated with significantly shorter DFS and DSS. On the grounds of our results, a discordance between cTNM and pTNM classification of the primary tumor seems to be an important prognostic factor and should be considered in the therapeutic decision making. Other significant prognostic factors with a negative influence on DSS were the stage of the primary tumor, the nodal status and postoperative radiotherapy. These results are unambiguously in agreement with current literature; as the extent of the primary tumor as well as the state of neck lymph nodes are considered prognostically significant factors $[21,22]$. Postoperative radiotherapy obviously does not influence the therapy results in a negative way; in this case, there is a worse prognosis due to other negative prognostic factors that played a crucial role when indicating postoperative radiotherapy (the extent of the primary tumor, the state of neck lymph nodes, the presence of vascular or perineural invasion and the like). In our study, the positivity of histological margins did not show any negative influence on the treatment results (either DFS or DSS). This result is in contradiction to current literature which considers histological margins a significant negative prognostic factor $[21,22]$. This can be explained by the strict indication for postoperative radiotherapy in those patients in our set who had positive histological margins. We see the similar results of the treatment of glottic and supraglottic tumors explained by a lower incidence of supraglottic tumors and to some extent by the selection of patients (by the more frequent indication for primary radiotherapy in the case of the supraglottic location).

What seems to be a new fact, to the best of our knowledge not yet published in literature, is the evidence of a discordance between clinical and pathological TNM classification as a significant prognostic factor; both in terms of the recurrence of the primary disease and specific survival of patients. The practical impact of our findings should consist in a more frequent indication for postoperative radiotherapy (or radiochemotherapy) in patients with a discordance between cTNM and pTNM; especially when the TNM stage increases within the postoperative classification.

\section{Conclusion}

A discordance between clinical and pathological TNM staging affects the results of cancer treatment significantly. Some improvement can be probably achieved with a higher accuracy of the preoperative diagnostic method.

Acknowledgements: The study was supported by the project (Ministry of Health, Czech Republic) for conceptual development of research organization 00179906 (research number 8151 ) and by the project BBMRI LM2010004.

\section{References}

[1] SOBIN LH, GOSPODAROWICZ MK, WITTEKIND C. In: JD. Brierley, MK. Gospodarowicz, C Wittekind (Eds.). TNM Classification of Malignant Tumours, 7th Edition. New York: Wiley-Blackwell; 2009, pp 336. ISBN 978-1-4443-3241-4

[2] HARREUS U. Surgical errors and risks- the head and neck cancer patient. GMS Curr Top Otorhinolaryngol Head Neck Surg. 2013; 12: Doc04.

[3] ZBAREN P, BECKER M, LANG H. Pretherapeutic staging of laryngeal carcinoma. Clinical findings, computed tomography, and magnetic resonance imaging compared with histopathology. Cancer. 1996; 77: 1263-1273. https://doi. org/10.1002/(SICI)1097-0142(19960401)77:7<1263::AIDCNCR6>3.0.CO;2-I

[4] ZBAREN P, BECKER M, LANG H. Staging of laryngeal cancer: endoscopy, computed tomography and magnetic resonance versus histopathology. Eur Arch Otorhinolaryngol. 1997; 254 Suppl 1: S117-122. https://doi.org/10.1007/ $\underline{B F 02439740}$

[5] KIM JW, YOON SY, PARK IS, PARK SW, KIM YM. Correlation between radiological images and pathological results in supraglottic cancer. J Laryngol Otol. 2008; 122: 1224-1229. https://doi.org/10.1017/S0022215108001746

[6] KUNO H, ONAYA H, FUJII S, OJIRI H, OTANI K et al. Primary staging of laryngeal and hypopharyngeal cancer: CT, MR imaging and dual-energy CT. Eur J Radiol 2014; 83: e23-35. https://doi.org/10.1016/j.ejrad.2013.10.022

[7] FOUCHER M, BARNOUD R, BUIRET G, PIGNAT JC, POUPART M. Pre- and posttherapeutic staging of laryngeal carcinoma involving anterior commissure: review of 127 cases. ISRN Otolaryngol. 2012; 2012: 363148. https://doi. org/10.5402/2012/363148

[8] DAISNE JF, DUPREZ T, WEYNAND B, LONNEUX M, HAMOIR $M$ et al. Tumor volume in pharyngolaryngeal squamous cell carcinoma: comparison at CT, MR imaging, and FDG PET and validation with surgical specimen. Radiology. 2004; 233: 93-100. https://doi.org/10.1148/radiol.2331030660

[9] ASHRAF M, BISWAS J, JHA J, NAYAK S, SINGH V et al. Clinical utility and prospective comparison of ultrasonography and computed tomography imaging in staging of neck metastases in head and neck squamous cell cancer in an Indian setup. Int J Clin Oncol 2011; 16: 686-693. https:// doi.org/10.1007/s10147-011-0250-2

[10] BARRERA JE, MILLER ME, SAID S, JAFEK BW, CAMPANA JP et al. Detection of occult cervical micrometastases in patients with head and neck squamous cell cancer. Laryngoscope 2003; 113: 892-896. https://doi.org/10.1097/00005537200305000-00022

[11] FERLITO A, PARTRIDGE M, BRENNAN J, HAMAKAWA H. Lymph node micrometastases in head and neck cancer: a review. Acta Otolaryngol 2001; 121: 660-665. https://doi. org/10.1080/00016480152583584 
[12] CELAKOVSKY P, KALFERT D, SMATANOVA K, CHROBOK V, LACO J. Detection of Cervical Lymph Node Micrometastases in Patients with Squamous Cell Carcinoma of the Oral Cavity, Pharynx and Larynx. Acta Medica (Hradec Kralove). 2015; 58: 62-65. https://doi. org/10.14712/18059694.2015.95

[13] HAMAKAWA H, FUKUZUMI M, BAO Y, SUMIDA T, KAYAHARA $\mathrm{H}$ et al. Keratin mRNA for detecting micrometastasis in cervical lymph nodes of oral cancer. Cancer Lett 2000; 160: 115-123. https://doi.org/10.1016/S0304-3835(00)00574-7

[14] NIEUWENHUIS EJ, LEEMANS CR, KUMMER JA, DENKERS F, SNOW GB et al. Assessment and clinical significance of micrometastases in lymph nodes of head and neck cancer patients detected by E48 (Ly-6D) quantitative reverse transcription-polymerase chain reaction. Lab Invest 2003; 83: 1233-1240. https://doi.org/10.1097/01. LAB. 0000083532.46536 .56

[15] TSUJIMOTO M, NAKABAYASHI K, YOSHIDOME K, KANEKO T, IWASE T et al. One-step nucleic acid amplification for intraoperative detection of lymph node metastasis in breast cancer patients. Clin Cancer Res 2007; 13: 4807-4816. https://doi.org/10.1158/1078-0432.CCR-06-2512

[16] DE WAAL PJ, FAGAN JJ, ISAACS S. Pre- and intraoperative staging of the neck in a developing world practice. J Laryngol Otol 2003; 117: 976-978. https://doi. org/10.1258/002221503322683876
[17] FERLITO A, SHAHA AR, RINALDO A. The incidence of lymph node micrometastases in patients pathologically staged N0 in cancer of oral cavity and oropharynx. Oral Oncol 2002; 38: 3-5. https://doi.org/10.1016/S1368-8375(01)00037-9

[18] MNEJJA M, HAMMAMI B, BOUGACHA L, CHAKROUN A, CHARFEDDINE I et al. Occult lymph node metastasis in laryngeal squamous cell carcinoma: Therapeutic and prognostic impact. Eur Ann Otorhinolaryngol Head Neck Dis 2010; 127: 173-176. https://doi.org/10.1016/j.anorl.2010.07.011

[19] RHEE D, WENIG BM, SMITH RV. The significance of immunohistochemically demonstrated nodal micrometastases in patients with squamous cell carcinoma of the head and neck. Laryngoscope 2002; 112: 1970-1974. https://doi. org/10.1097/00005537-200211000-00011

[20] KOCH WM, RIDGE JA, FORASTIERE A, MANOLA J. Comparison of clinical and pathological staging in head and neck squamous cell carcinoma: results from Intergroup Study ECOG 4393/RTOG 9614. Arch Otolaryngol Head Neck Surg. 2009; 135: 851-858. https://doi.org/10.1001/ archoto.2009.123

[21] MONTGOMERY PQ, EVANS PHR, GULLANE PJ. (Eds). Principles and Practice of Head and Neck Surgery and Oncology, 2nd Edition. Informa Healthcare, 2009, 658 p. ISBN 9780415444125

[22] GENDEN EM, VARVARES MA. (Eds). Head and Neck Cancer. An Evidence-Based Team Approach. New York - Stuttgart: Thieme, 2008, 217 pp. ISBN 9781588905086 